\title{
RESEARCH
}

Open Access

\section{Gender heterogeneity in dyslipidemia prevalence, trends with age and associated factors in middle age rural Chinese}

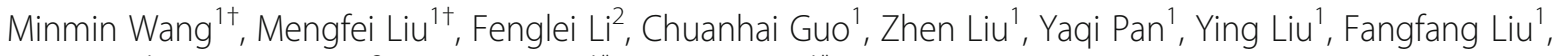
Hong Cai ${ }^{1}$, Yangfeng $\mathrm{Wu}^{3}$, Zhonghu $\mathrm{He}^{1 *}$ and Yang Ke

\begin{abstract}
Background: Heterogeneity should be carefully addressed to facilitate establishment of effective population-level blood lipid management. The primary aim of the study was to investigate gender heterogeneity in prevalence of dyslipidemia, including trends with age and associated factors in middle age rural Chinese.

Methods: This is a cross-sectional study based on a baseline investigation of a population-based randomized controlled trial in rural China, involving 26,378 permanent residents of age 45-69. The age-specific prevalence of dyslipidemia was estimated for men and women, and the trends of prevalence with age were compared. Logistic regression was used to explore the factors associated with prevalent risk of dyslipidemia.

Results: The overall prevalence of dyslipidemia was significantly higher in females than in males for borderline high and above (BHA) total cholesterol (TC $\geq 200 \mathrm{mg} / \mathrm{dL}$ ), BHA triglycerides ( $T \mathrm{G} \geq 150 \mathrm{mg} / \mathrm{dL}$ ) and BHA low-density lipoprotein cholesterol (LDL-C $\geq 130 \mathrm{mg} / \mathrm{dL}$ ), but was lower for low high-density lipoprotein cholesterol (HDL-C $<$ $40 \mathrm{mg} / \mathrm{dL}$ ) in females than the corresponding prevalence in males. The prevalence of borderline high and above TC, TG and LDL-C all rose with age in females, but was stable or even decreased with age in males. In contrast, graphic representation of the prevalence of low HDL-C showed no striking age related trend in both genders. Risk of dyslipidemia was associated predominantly with obesity in males, but was more predominantly associated with hypertension in females.

Conclusion: Heterogeneity was found in comparing the prevalence of dyslipidemia in men and women, and gender heterogeneity was found in its trend with age and associated factors in middle aged rural Chinese. The effectiveness of population-level blood lipid management and CVD primary prevention programs in China is expected to be improved if gender heterogeneity is considered.
\end{abstract}

Keywords: Lipid management, Gender heterogeneity, Dyslipidemia, Epidemiology, Lipids and lipoproteins, Prevalence, Risk factor

\footnotetext{
* Correspondence: zhonghuhe@foxmail.com; keyang@bjmu.edu.cn

${ }^{\dagger}$ Minmin Wang and Mengfei Liu contributed equally to this work.

${ }^{1}$ Key Laboratory of Carcinogenesis and Translational Research (Ministry of

Education/Beijing), Laboratory of Genetics, Peking University Cancer Hospital

and Institute, Beijing, China

Full list of author information is available at the end of the article
}

(C) The Author(s). 2020 Open Access This article is licensed under a Creative Commons Attribution 4.0 International License, which permits use, sharing, adaptation, distribution and reproduction in any medium or format, as long as you give appropriate credit to the original author(s) and the source, provide a link to the Creative Commons licence, and indicate if changes were made. The images or other third party material in this article are included in the article's Creative Commons licence, unless indicated otherwise in a credit line to the material. If material is not included in the article's Creative Commons licence and your intended use is not permitted by statutory regulation or exceeds the permitted use, you will need to obtain permission directly from the copyright holder. To view a copy of this licence, visit http://creativecommons.org/licenses/by/4.0/ The Creative Commons Public Domain Dedication waiver (http://creativecommons.org/publicdomain/zero/1.0/) applies to the data made available in this article, unless otherwise stated in a credit line to the data. 


\section{Introduction}

Blood lipids are fatty substances free in the blood or bound to other molecules. Lipids play a significant role in energy storage, cell membrane structure, cytokine synthesis, signal transmission and overall basal metabolism [1]. Within numerous different lipids and lipoproteins, triglycerides (TG), total cholesterol (TC), and the two major components of TC namely low-density lipoprotein cholesterol (LDL-C) and high-density lipoprotein cholesterol (HDL-C), are the most commonly used indicators and control targets in clinical settings and population-level intervention projects.

Dyslipidemia is defined by an abnormal profile of blood lipids [2, 3], and dyslipidemia contributes significantly to atherosclerosis [4]. Elevated levels of plasma LDL-C, TC and TG have been shown to be crucial risk factors for cardiovascular disease (CVD) [5-7]. Basic data regarding prevalence and factors associated with these lipid indicators provides a foundation for establishing strategies for blood lipid management, and this is a key step in the primary prevention of CVD [8].

To date, several nation-wide population-based studies have been conducted in urban and rural areas to investigate the prevalence of dyslipidemia in Chinese adults. Previous studies have reported differing gender-specific prevalence in dyslipidemia in China [9-16]. For example, the 2010 Chinese Chronic Disease Survey which was based on data from 162 surveillance points $(59,001$ rural residents over 18 years) in 31 provinces, reported the prevalence of high $\mathrm{TC}$, high TG, high LDL-C and low HDL-C were $3.0,13.0,1.8,49.5 \%$ for males, and 2.7, 8.7, $1.7,39.5 \%$ for females in rural China [14]. However, the potential heterogeneity in prevalence of dyslipidemia in males vs. females has not been systematically evaluated.

A pilot blood lipid management project has been underway in China since 2013, and a nation-wide blood lipid management project is going to be initiated in the near future [17]. In this project, blood lipid management is targeted to the whole population, under the assumption that heterogeneity does not exist among subgroups of subjects $[18,19]$. One potential pitfall of using this "universal" strategy is the imprecision and lack of prioritizing in defining populations to be intervened. This defect would be greatly enlarged in case that heterogeneity of dyslipidemia prevalence exists in subgroup(s) of subjects with particular demographic characteristics. The heterogeneity of prevalence and risk factor profiles of dyslipidemia should be carefully addressed to facilitate establishment of effective population-level blood lipid management and a CVD primary prevention strategy.

In this study, the prevalence of dyslipidemia in $\mathrm{TC}$, TG, LDL-C and HDL-C was investigated in a rural Chinese population based on a large-scale populationbased randomized controlled trial. The prevalence and trends with age for these four commonly used indicators in men vs. women were evaluated, and the heterogeneity in risk factor patterns for dyslipidemia in males and females was assessed.

\section{Methods \\ Parent study}

In 2012, the Endoscopic Screening for Esophageal Cancer in China (ESECC) randomized controlled trial (ClinicalTrials.gov identifier: NCT01688908) [20] was initiated in Hua County, which aimed to evaluate the efficacy and cost-effectiveness of endoscopic screening for Esophageal Squamous Cell Carcinoma. The design and preliminary results of this ESECC trial can be found elsewhere [20]. Briefly, 668 out of 846 villages in rural Hua County with population size ranging from 500 to 3000 were randomly selected and allocated into the intervention or control arm of the study at a ratio of 1:1, using a blocked randomization procedure based on the total population size of each village. In the baseline investigation of this ESECC trial, a total of 35,772 permanent residents aged 45-69 in these target villages signed an informed consent form to participate and provided blood samples. This included about $20 \%$ of all eligible residents in the target villages.

\section{Study design and participants}

The current study is a cross-sectional survey based on baseline investigation data of the ESECC trial. Eligibility criteria for this study included: 1) permanent residency in a target village; 2 ) age 45-69; 3) signed informed consent for participation; 4) questionnaire completed; 5) blood samples provided, with valid test results for blood lipids. A total of 26,378 subjects in the baseline investigation of the ESECC trial were enrolled in this study (see Supplementary Figure 1).

\section{Physical examination and questionnaire interview}

All participants in this study received a measurement of height and weight in baseline investigation. Participants' seated blood pressure was measured once after 5 min of rest with mercury sphygmomanometer. A computeraided one-on-one questionnaire was then conducted by well-trained interviewers to collect information on personal characteristics (e.g. age and gender) and socioeconomic status (level of education, family size, work type, annual income per capital and marital status), lifestyle factors (cigarette smoking, alcohol consumption, source of drinking water and intake of fruit, vegetable, protein, fried food, salty food and spicy food) and health status (self-reported CVD history, history of diabetes and symptoms of heartburn and regurgitation). Detailed definitions and coding for potential risk factors of 
dyslipidemia evaluated in this study are listed in Supplementary Table 1.

\section{Blood lipid measurement}

At physical examination, a fasting blood sample of $\sim 5$ $\mathrm{mL}$ was collected from each participant in a heparin sodium anticoagulant tube. These tubes were then centrifuged at $1000 \mathrm{rpm}$ for $5 \mathrm{~min}$ and the supernatant was sent for lipid measurement of TC, LDL-C, HDL-C and TG within $4 \mathrm{~h}$ in the clinical laboratory of Hua County People's Hospital. Lipid measurements were conducted using a HITACHI7600 automatic biochemistry analyzer (Hitachi High Technologies Co., Tokyo, Japan) with commercially available reagents (Autobio Diagnostics Co., Ltd., Beijing, China) for analysis of TC, TG, LDL-C and HDL-C.

\section{Definition of dyslipidemia}

According to the guidelines for the prevention and treatment of dyslipidemia in Chinese adults (2016 version) [3], borderline high TC was defined as $\geq 200 \mathrm{mg} / \mathrm{dL}$ (5.2 $\mathrm{mmol} / \mathrm{L})$ and $<240 \mathrm{mg} / \mathrm{dL}(6.2 \mathrm{mmol} / \mathrm{L})$; high $\mathrm{TC}$ as $\geq 240 \mathrm{mg} / \mathrm{dL}(6.2 \mathrm{mmol} / \mathrm{L})$; borderline high TG as $\geq 150$ $\mathrm{mg} / \mathrm{dL}(1.7 \mathrm{mmol} / \mathrm{L})$ and $<200 \mathrm{mg} / \mathrm{dL}(2.3 \mathrm{mmol} / \mathrm{L})$; high TG as $\geq 200 \mathrm{mg} / \mathrm{dL}(2.3 \mathrm{mmol} / \mathrm{L})$; borderline high LDL-C as $\quad \geq 130 \mathrm{mg} / \mathrm{dL} \quad(3.4 \mathrm{mmol} / \mathrm{L}) \quad$ and $<160 \mathrm{mg} / \mathrm{dL} \quad(4.1$ $\mathrm{mmol} / \mathrm{L})$; high LDL-C as $\geq 160 \mathrm{mg} / \mathrm{dL}(4.1 \mathrm{mmol} / \mathrm{L})$; low $\mathrm{HDL}-\mathrm{C}$ as $<40 \mathrm{mg} / \mathrm{dL}(1.0 \mathrm{mmol} / \mathrm{L})$. In consideration of discrepancies in biologic function and the notable heterogeneity of age distribution between HDL-C and the other three indicators (see Fig. 1), dyslipidemia was defined on the basis of only TC, TG and LDL-C. Two sets of definitions of dyslipidemia were used in this study, namely borderline high and above (BHA) dyslipidemia, and high dyslipidemia. BHA dyslipidemia was defined as the presence of a high level or borderline high level of any factor including TC, TG or LDL-C, and high dyslipidemia was defined as the presence of a high level of any one of these three lipid factors in a given study subject.

\section{Statistical analysis}

The Chi-square test and Student's $t$ test were used to compare demographic characteristics and behavioral factors in ESECC participants who were enrolled and not enrolled, as well as among male and female subjects included in this study. Gender stratified prevalence of lipid abnormalities was estimated for TC, TG, LDL-C, HDLC, BHA dyslipidemia and high dyslipidemia, and difference in the distribution of these prevalence estimates in males vs. females was assessed using the Chi-square test for dichotomous variables and Ridit analysis for multicategorical variables. For age related trends, a cubic polynomial curve was applied to reduce random fluctuations, and the significance of heterogeneity was tested by fitting models with age and gender and the interaction terms of age and gender variables. Univariate and multiple unconditional logistic regression models were applied to identify factors associated with 'borderline high and above (BHA) dyslipidemia' and 'high dyslipidemia' separately. First a multiple model was constructed based on all the participants, and gender heterogeneity in the effect of each risk factor was tested by adding the interaction term of the specific risk factor (one term at a time) and gender variable into the final model. As significant interactions between important behavior factors and gender were found (see below), risk factors were identified separately in males and females with logistic regression analysis. Statistical analysis was performed using STATA (Version 13.1; Stata Corp LLC, TX, USA). All tests were two-sided and $P$ values $<0.05$ were considered to be statistically significant.

\section{Results}

Key demographic characteristics and behavior variables were compared between ESECC participants enrolled in and excluded from this study (Supplementary Table 2). The distribution of age, gender, job, smoking, alcohol consumption, fried food intake, spicy food intake and self-reported history of diabetes were similar between the two groups. Whereas there were differences between the two groups for education, BMI, blood pressure, water source and heartburn and regurgitation. Of the 26, 378 subjects enrolled in this study, 12,925 (49.00\%) were men and 13,453 (51.00\%) were women. Compared with females, male participants were slightly older, more likely to have a non-physical job, more likely to smoke, consumed more alcohol, were more likely to have hypertension, ate more fried and spicy food, and a higher proportion of these individuals had heartburn and regurgitation. The proportion of individuals with obesity and a self-reported history of diabetes was higher in females than that in males. In evaluation of the four lipid indicators, females had significantly higher levels of TC, LDL-C and HDL-C compared with male participants $(P<0.001)$. TG did not show a statistically significant difference in genders (Table 1).

Table 2 shows prevalence of lipid abnormalities stratified by gender (detailed gender- and age-specific prevalence are recorded in Supplementary Table 3). The prevalence of borderline high $\mathrm{TC}$, high $\mathrm{TC}$, borderline high TG, high TG, borderline high LDL-C, high LDL-C and low HDL-C in this rural population was $24.53,7.50$, $15.89,14.53,7.81,1.76$, and $9.19 \%$ respectively. For dyslipidemia as defined in this study, the prevalence of BHA dyslipidemia and high dyslipidemia was 48.68 and $19.90 \%$ respectively. Regarding the heterogeneity between genders, prevalence estimates of all the lipid indicators showed significant difference in males and 


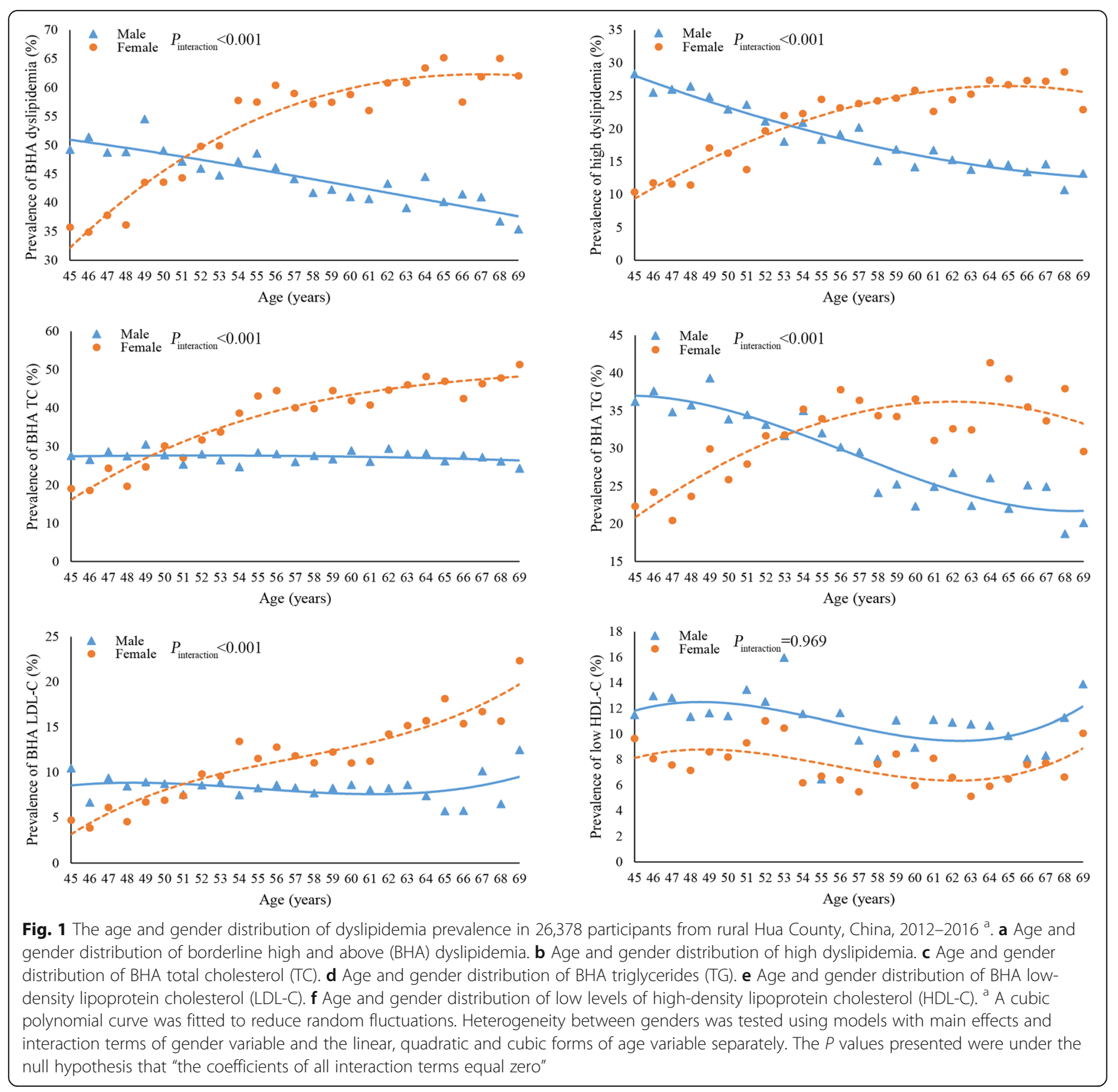

females. Specifically, females had a higher proportion of abnormalities in TG, TC and LDL-C, but a lower proportion of HDL-C abnormalities compared with the corresponding prevalence in males (Table 2).

As shown in Fig. 1c-e, the age related trend for prevalence of the BHA status of TC, TG and LDL-C demonstrated a "scissor-shaped" cross pattern between genders: the prevalence of BHA TC, TG and LDL-C rose with increasing age in females but remained stable or even decreased in males, resulting in intersection of these two curves in the 50-55-year age group $\left(P_{\text {interaction }}<0.001\right)$. Similar scissor-shaped patterns were also observed for BHA dyslipidemia and high dyslipidemia as defined in this study (Fig. 1a-b), and high-level groups in TC, TG and LDL-C (Supplementary Figure 2). In contrast, the prevalence of low HDL-C showed no striking increasing or decreasing trend with age in males and females in this study (Fig. 1f, $P_{\text {interaction }}=0.969$ ).

For factors associated with BHA dyslipidemia, significant heterogeneity in OR estimates of age, BMI and blood pressure was found in males vs. females. The risk of dyslipidemia was associated predominantly with obesity in males, but was more predominantly associated with hypertension in females (Table 3). In view of these differences, multiple logistic regression models were fitted in males and females separately (Table 3 ). For males, 
Table 1 Selected demographic and behavioral characteristics in 26,378 individuals from rural Hua County, China, 2012-2016

\begin{tabular}{|c|c|c|c|c|}
\hline & $\begin{array}{l}\text { Participants in this study } \\
(N=26,378) \\
\mathrm{n}(\%)\end{array}$ & $\begin{array}{l}\text { Male } \\
(N=12,925) \\
n(\%)\end{array}$ & $\begin{array}{l}\text { Female } \\
(N=13,453) \\
\mathrm{n}(\%)\end{array}$ & $P$ value $^{a}$ \\
\hline \multicolumn{5}{|l|}{ Age } \\
\hline Mean (SD) & $56.52(6.88)$ & $56.84(6.87)$ & $56.21(6.88)$ & $<0.001$ \\
\hline \multicolumn{5}{|l|}{ Educational level } \\
\hline Illiterate & $8537(32.36)$ & $1901(14.71)$ & $6636(49.33)$ & \multirow[t]{3}{*}{$<0.001$} \\
\hline Primary or Middle School & $15,252(57.82)$ & $9139(70.71)$ & $6113(45.44)$ & \\
\hline High school or above & $2589(9.81)$ & $1885(14.58)$ & $704(5.23)$ & \\
\hline \multicolumn{5}{|l|}{ Job } \\
\hline Physical labor & $25,909(98.22)$ & $12,544(97.05)$ & 13,365 (99.35) & \multirow[t]{2}{*}{$<0.001$} \\
\hline Nonphysical work & $469(1.78)$ & $381(2.95)$ & $88(0.65)$ & \\
\hline \multicolumn{5}{|l|}{ Body mass index ${ }^{c}$} \\
\hline$\leq 24.0 \mathrm{~kg} / \mathrm{m}^{2}$ & $9808(37.18)$ & $4811(37.22)$ & 4997 (37.14) & \multirow[t]{4}{*}{0.013} \\
\hline $24.1-27.9 \mathrm{~kg} / \mathrm{m}^{2}$ & $10,869(41.20)$ & $5394(41.73)$ & $5475(40.70)$ & \\
\hline$\geq 28.0 \mathrm{~kg} / \mathrm{m}^{2}$ & $5618(21.30)$ & $2670(20.66)$ & $2948(21.91)$ & \\
\hline Unknown ${ }^{b}$ & $83(0.31)$ & $50(0.39)$ & $33(0.25)$ & \\
\hline \multicolumn{5}{|l|}{ Blood pressure $^{d}$} \\
\hline No hypertension & $12,019(45.56)$ & $5582(43.19)$ & $6437(47.85)$ & \multirow[t]{3}{*}{$<0.001$} \\
\hline Hypertension & $14,212(53.88)$ & $7260(56.17)$ & $6952(51.68)$ & \\
\hline Unknown ${ }^{b}$ & $147(0.56)$ & $83(0.64)$ & $64(0.48)$ & \\
\hline \multicolumn{5}{|l|}{ Water source ${ }^{e}$} \\
\hline Deep well & $17,475(66.25)$ & $8553(66.17)$ & $8922(66.32)$ & \multirow[t]{2}{*}{0.802} \\
\hline Shallow well or other & $8903(33.75)$ & $4372(33.83)$ & $4531(33.68)$ & \\
\hline \multicolumn{5}{|l|}{ Smoking ${ }^{f}$} \\
\hline None & $17,269(65.47)$ & $3968(30.70)$ & $13,301(98.87)$ & \multirow[t]{4}{*}{$<0.001$} \\
\hline Moderate & $6797(25.77)$ & $6657(51.50)$ & $140(1.04)$ & \\
\hline Large amount & $2265(8.59)$ & $2255(17.45)$ & $10(0.07)$ & \\
\hline Unknown ${ }^{b}$ & $47(0.18)$ & $45(0.35)$ & $2(0.01)$ & \\
\hline \multicolumn{5}{|l|}{ Alcohol consumption ${ }^{9}$} \\
\hline None & $20,569(77.98)$ & $7196(55.68)$ & $13,373(99.41)$ & \multirow[t]{4}{*}{$<0.001$} \\
\hline Moderate & $4351(16.49)$ & $4277(33.09)$ & $74(0.55)$ & \\
\hline Large amount & $1445(5.48)$ & $1441(11.15)$ & $4(0.03)$ & \\
\hline Unknown $^{\mathrm{b}}$ & $13(0.05)$ & $11(0.09)$ & $2(0.01)$ & \\
\hline \multicolumn{5}{|l|}{ Fried food intake } \\
\hline Seldom & $18,767(71.15)$ & $8843(68.42)$ & $9924(73.77)$ & \multirow[t]{2}{*}{$<0.001$} \\
\hline Often & $7611(28.85)$ & $4082(31.58)$ & $3529(26.23)$ & \\
\hline \multicolumn{5}{|l|}{ Spicy food intake } \\
\hline Seldom & $16,888(64.02)$ & $8093(62.62)$ & $8795(65.38)$ & \multirow[t]{2}{*}{$<0.001$} \\
\hline Often & $9490(35.98)$ & $4832(37.38)$ & $4658(34.62)$ & \\
\hline \multicolumn{5}{|l|}{ Heartburn and regurgitation } \\
\hline No & $19,193(72.76)$ & $9220(71.33)$ & $9973(74.13)$ & \multirow[t]{2}{*}{$<0.001$} \\
\hline Yes & $7185(27.24)$ & $3705(28.67)$ & $3480(25.87)$ & \\
\hline \multicolumn{5}{|c|}{ Self-reported history of diabetes } \\
\hline No & 25,834 (97.94) & $12,684(98.14)$ & $13,150(97.75)$ & \multirow[t]{2}{*}{0.027} \\
\hline Yes & $544(2.06)$ & $241(1.86)$ & $303(2.25)$ & \\
\hline
\end{tabular}


Table 1 Selected demographic and behavioral characteristics in 26,378 individuals from rural Hua County, China, 2012-2016 (Continued)

\begin{tabular}{|c|c|c|c|c|}
\hline & $\begin{array}{l}\text { Participants in this study } \\
(N=26,378) \\
n(\%)\end{array}$ & $\begin{array}{l}\text { Male } \\
(N=12,925) \\
\mathrm{n}(\%)\end{array}$ & $\begin{array}{l}\text { Female } \\
(N=13,453) \\
\mathrm{n}(\%)\end{array}$ & $P$ value \\
\hline \multicolumn{5}{|c|}{ TC level $(\mathrm{mg} / \mathrm{dL})^{\mathrm{h}}$} \\
\hline Mean (SD) & 186.49 (35.67) & 182.26 (34.90) & 190.55 (35.93) & $<0.001$ \\
\hline \multicolumn{5}{|c|}{ TG level (mg/dL) ${ }^{i}$} \\
\hline Mean (SD) & $139.46(111.86)$ & $140.20(129.57)$ & 138.76 (91.68) & 0.297 \\
\hline \multicolumn{5}{|c|}{ LDL-C level (mg/dL) ${ }^{h}$} \\
\hline Mean (SD) & $97.67(25.27)$ & $95.95(24.84)$ & $99.32(25.57)$ & $<0.001$ \\
\hline \multicolumn{5}{|c|}{$\mathrm{HDL}-\mathrm{C}$ level $(\mathrm{mg} / \mathrm{dL})^{h}$} \\
\hline Mean (SD) & $52.73(14.08)$ & $51.92(14.26)$ & $53.50(13.86)$ & $<0.001$ \\
\hline \multicolumn{5}{|c|}{ 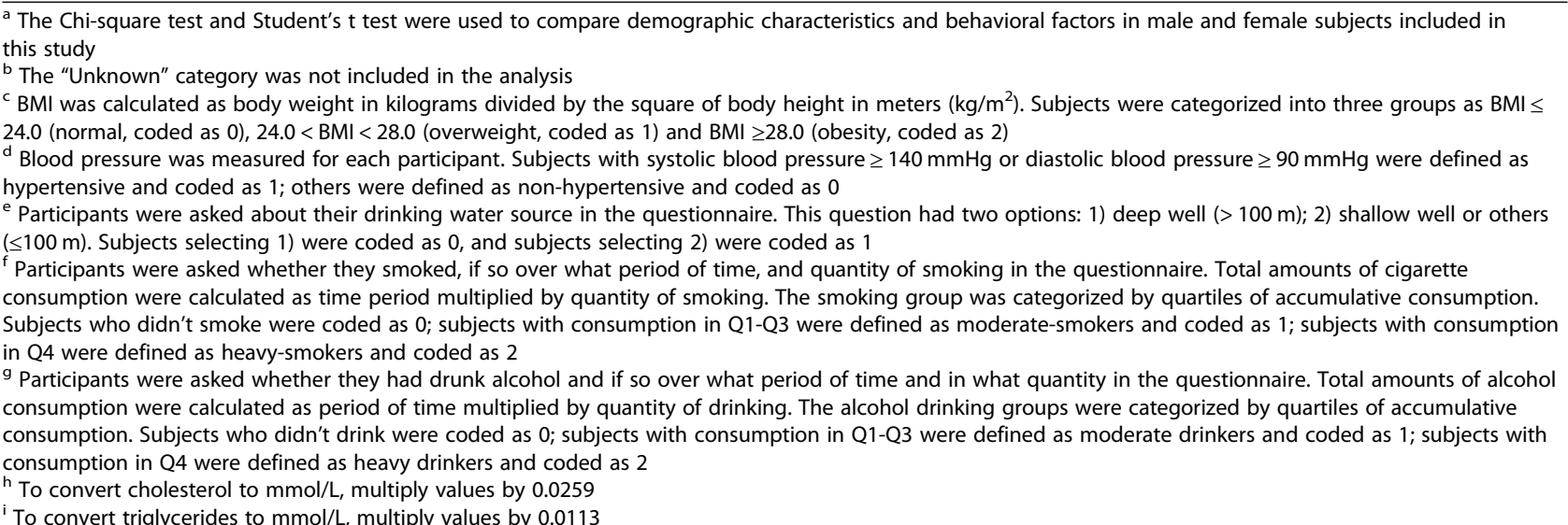 } \\
\hline
\end{tabular}

Table 2 Gender-specific prevalence of dyslipidemia in 26,378 individuals from rural Hua County, China, 2012-2016

\begin{tabular}{|c|c|c|c|c|c|}
\hline Indicator & Classification & $\begin{array}{l}\text { Total } n(\%) \\
(\mathrm{N}=26,378)\end{array}$ & $\begin{array}{l}\text { Male } \mathrm{n}(\%) \\
(\mathrm{N}=12,925)\end{array}$ & $\begin{array}{l}\text { Female } n(\%) \\
(N=13,453)\end{array}$ & $P$ value $^{a}$ \\
\hline \multirow[t]{3}{*}{ TC } & Ideal & $17,930(67.97)$ & $9374(72.53)$ & $8556(63.60)$ & $<0.001$ \\
\hline & Borderline high & $6470(24.53)$ & $2799(21.66)$ & $3671(27.29)$ & \\
\hline & High & $1978(7.50)$ & $752(5.82)$ & $1226(9.11)$ & \\
\hline \multirow[t]{3}{*}{ TG } & Ideal & $18,353(69.58)$ & $9165(70.91)$ & $9188(68.30)$ & 0.004 \\
\hline & Borderline high & $4192(15.89)$ & $1837(14.21)$ & $2355(17.51)$ & \\
\hline & High & $3833(14.53)$ & $1923(14.88)$ & $1910(14.20)$ & \\
\hline \multirow[t]{3}{*}{ LDL-C } & Ideal & 23,854 (90.43) & $11,864(91.79)$ & $11,990(89.13)$ & $<0.001$ \\
\hline & Borderline high & $2059(7.81)$ & $863(6.68)$ & $1196(8.89)$ & \\
\hline & High & $465(1.76)$ & 198 (1.53) & $267(1.98)$ & \\
\hline \multirow[t]{2}{*}{$\mathrm{HDL}-\mathrm{C}$} & Normal & $23,955(90.81)$ & $11,521(89.14)$ & $12,434(92.43)$ & $<0.001$ \\
\hline & Low & $2423(9.19)$ & $1404(10.86)$ & $1019(7.57)$ & \\
\hline \multirow[t]{2}{*}{ BHA dyslipidemia ${ }^{\text {b }}$} & Normal & $13,538(51.32)$ & $7146(55.29)$ & $6392(47.51)$ & $<0.001$ \\
\hline & Abnormal & $12,840(48.68)$ & $5779(44.71)$ & $7061(52.49)$ & \\
\hline \multirow[t]{2}{*}{ High dyslipidemia ${ }^{c}$} & Normal & $21,129(80.10)$ & $10,494(81.19)$ & $10,635(79.05)$ & $<0.001$ \\
\hline & Abnormal & 5249 (19.90) & 2431 (18.81) & $2818(20.95)$ & \\
\hline
\end{tabular}

\footnotetext{
${ }^{a} P$ values were derived from the Chi-square test or Ridit test
}

${ }^{\mathrm{b}} \mathrm{BHA}$ (borderline high and above) dyslipidemia was defined as presence of borderline high or high level in any one of the factors TC, TG or LDL-C

c High dyslipidemia was defined as presence of high level of any one of TC, TG or LDL-C 


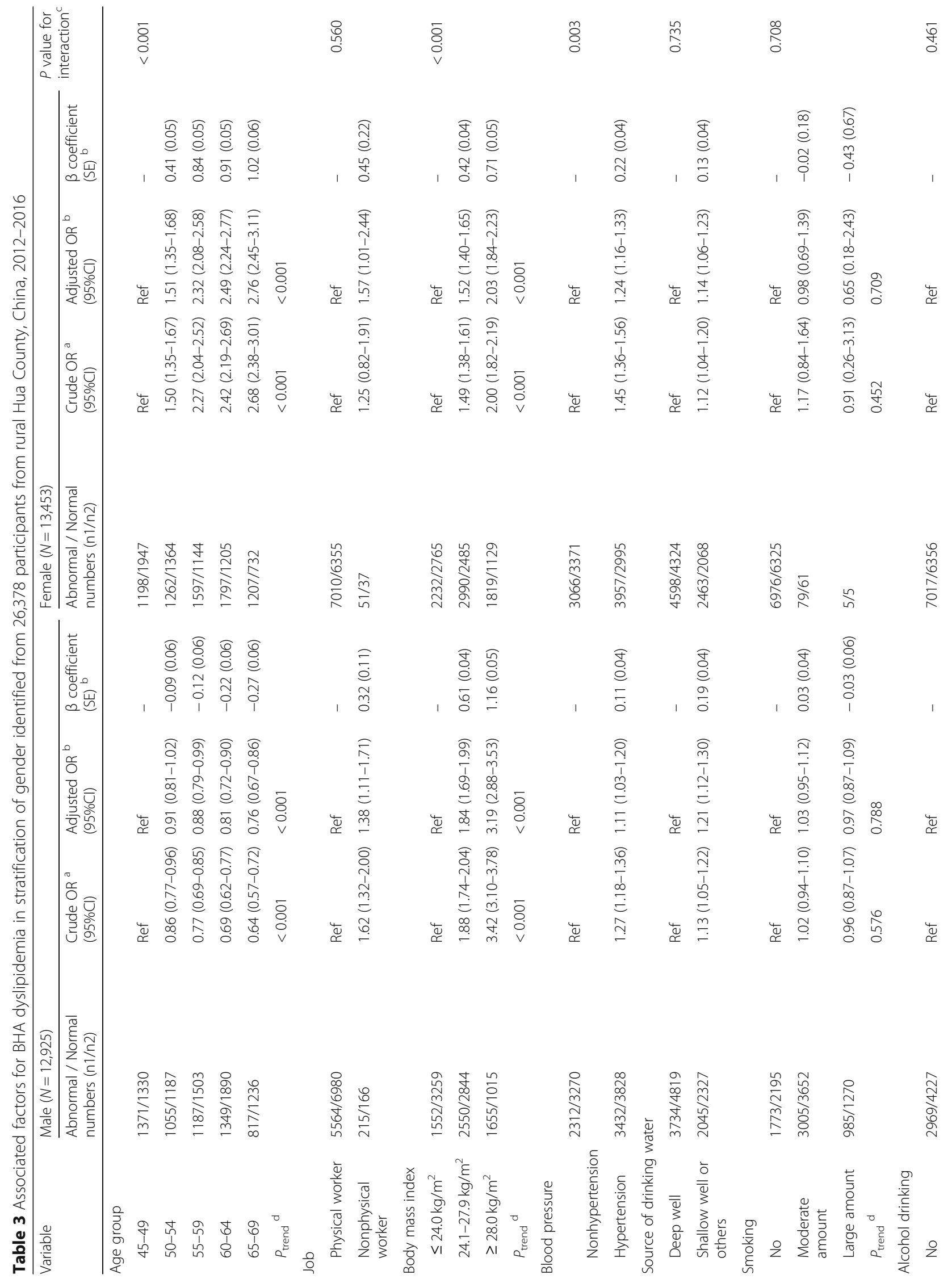




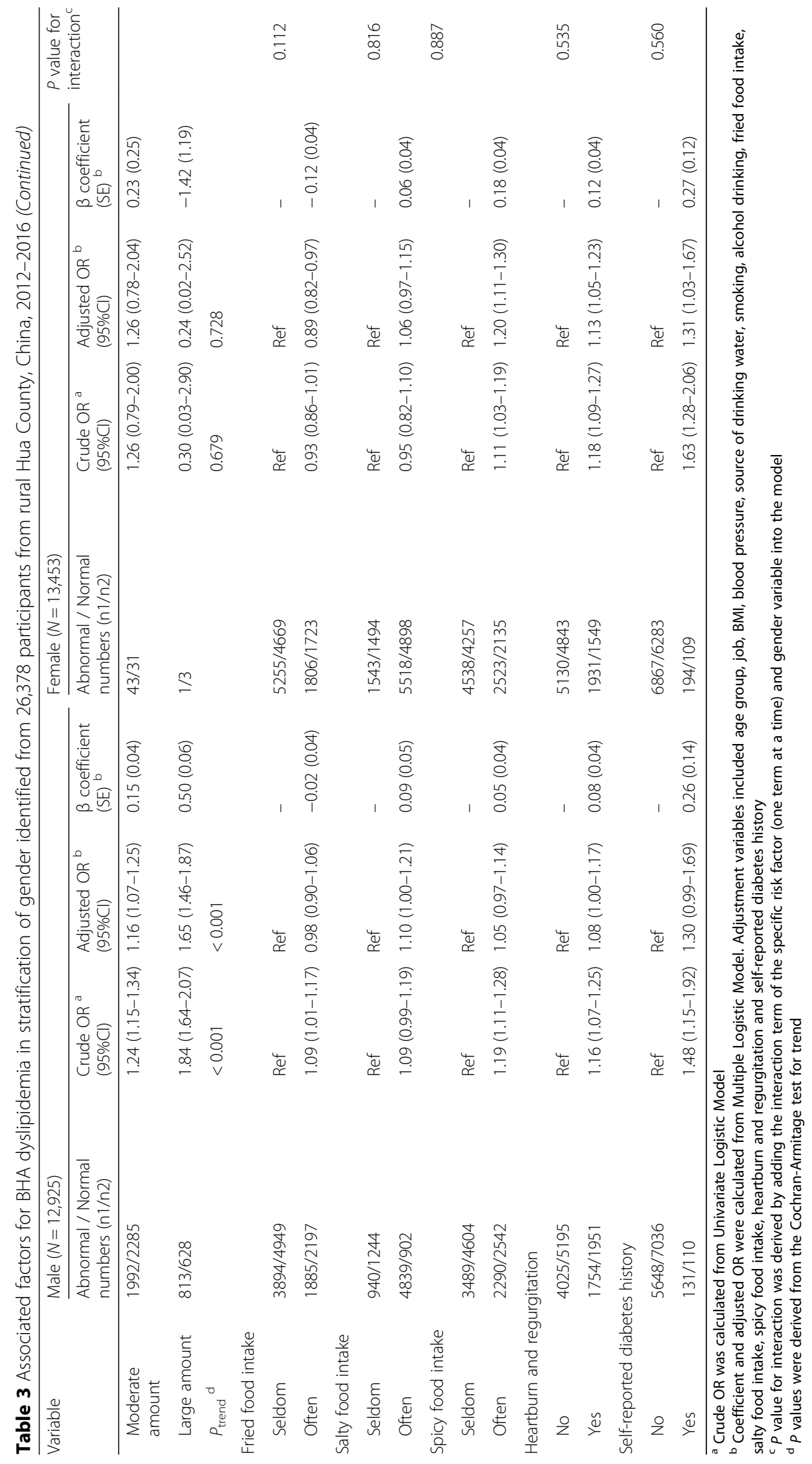


younger age, nonphysical work, higher BMI, hypertension, use of a shallow well as a main source of drinking water, alcohol use, more salty food intake and symptoms of heartburn and regurgitation were associated with an increased risk of BHA dyslipidemia. Risk factors for BHA dyslipidemia in females included older age, nonphysical work, higher BMI, hypertension, use of a shallow well as a main source of drinking water, less intake of fried food, more intake of spicy food, symptoms of heartburn and regurgitation and a self-reported history of diabetes (Table 3). Similar risk factor patterns were observed in models taking high dyslipidemia as a dependent variable (Supplementary Table 4).

\section{Discussion}

Mortality associated with CVD has risen in China over the last decade, and has become the leading cause of mortality and accounts for over $40 \%$ of deaths from all causes in 2014 [21, 22]. Blood lipids are a principal contributor to the onset of CVD, and control of these factors has increasingly been a concern of health policy makers in China. Guidelines for prevention and treatment of dyslipidemia in Chinese adults were established in 2007 [2, 3]. The first-phase pilot community-based blood lipid management project was completed in 2013-2016 in urban areas of China (Beijing, Hangzhou and Shenzhen City), and the second-phase of this project is now underway in rural areas [17]. However, the practice of dyslipidemia management is still limited in rural China. Due to the large number of residents, the relatively low level of economic development and limited access to health resources in rural areas, establishment of a population-level blood lipid management project requires great circumspection. This study for the first time systematically evaluated the gender heterogeneity in prevalence of dyslipidemia, trends of dyslipidemia with age, and associated factors based on data from a largescale population-based study in rural China. Findings from this study have shed light on the potential for a "tailored" strategy of dyslipidemia management.

A significant finding of this study was the heterogeneity regarding trend with age of dyslipidemia in males and females in middle aged rural Chinese. Prevalence of dyslipidemia was significantly higher in females in the whole population under study, but it demonstrates a "scissor shaped" trend with age between genders, which crossed at the age of 50-55 years. Although this gender associated heterogeneity has not been previously well recognized, there have been similar results in population-based surveys in China. Studies by Zhang M et al., Pan L et al. and Qi L et al. [9-11] with representative sampling framework demonstrated that the prevalence of high TC, TG and LDL-C increase with age in females but are stable or decreased in males in subjects of 40-70 years, and showed a "scissor shaped" pattern very similar to that observed in our study population (Supplementary Figure 3A-D \& E-H \& I). Investigations in Korea [23, 24], Brazil [25] and India [26] have also reported that age trend of abnormal TC, TG or LDL-C showed a "scissor-shaped" pattern between genders. Mechanisms underlying this "scissor shaped" age related trend of prevalence in dyslipidemia between genders are not completely clear. Possible explanations for this trend of increase in females include menopausal transition and loss of estrogen, which might act as a trigger factor and enhance metabolic dysfunction [27-30]. However, considering blood lipid management, greater attention should be given to males aged $45-50$ years and females over 50 in both dyslipidemia screening and intervention in rural China, since these subgroups of individuals were at the highest risk of having dyslipidemia in males and females aged 45-69, respectively.

This study identified several well-established contributing factors for dyslipidemia (e.g. nonphysical work, obesity, hypertension) $[12,13,31]$ as well as several gender specific factors. Gender-specific risk factors included alcohol consumption and salty food intake in males, and spicy food intake and self-reported diabetes history in females. It is of interest that the association of dyslipidemia with BMI and blood pressure is modified by gender. Risk of dyslipidemia was associated predominantly with obesity in males, but was more predominantly associated with hypertension in females. The genderspecific risk factor patterns may be useful in identification of a target population for dyslipidemia screening or intervention in the lipid management project.

According to findings of this study, it is proposed that gender specific pattern of dyslipidemia should be taken into careful consideration in population-level blood lipid management and CVD prevention projects in rural China, as: 1) The averaged disease burden (overall prevalence) estimated over the whole population may not in fact represent the situation for either males or females. 2) From the point of project implementation, imprecision in targeting a high-risk population may lead to lack of prioritization and impair the effect of the project.

Results from this study showed that prevalence of HDL-C abnormality had a completely different agerelated trend as compared to that of TC, TG and LDLC. The prevalence of low HDL-C was higher in males than that in females with a relatively fixed absolute difference, which showed two parallel curves without striking increasing or decreasing trend with age in both genders. This distinct pattern of HDL-C as compared to TC, TG and LDL-C was also suggested in previous population-based investigations in China $[9,10]$ (Supplementary Figure 3D \& H). Unlike the other three lipid indicators [32, 33], the biologic function of HDL-C is still 
unclear and the causal relationship between HDL-C and CVD is uncertain [34]. Several randomized trials using drugs which increase HDL-C failed to show a reduction in CVD events or confer a cardiovascular benefit [3537]. This evidence indicated that HDL-C may have a unique biologic role in the lipid metabolism process. As such, dyslipidemia in this study was defined as the presence of a borderline high or high level of any one of TC, TG or LDL-C, not including HDL-C. It was different from other studies in which dyslipidemia was defined on the basis of four lipid indicators [10-12, 15].

\section{Study strengths and limitations}

This study is conducted based on a population-based randomized controlled trial with strict quality control, which ensures a good representation of the study population and the reliability of data collected. This study also has limitations. First, this study enrolled only adults aged 45-69, and did not evaluate heterogeneity in prevalence of dyslipidemia in younger individuals. Second, ESECC participants accounted for about $20 \%$ of all eligible residents in target villages. Although the age and gender distributions of participants in this study are comparable with those in the entire population of Hua County (data not shown), potential selection bias cannot be ruled out. Third, this was a single-center crosssectional study, and further population-based multicenter studies would be required to confirm the heterogeneity of dyslipidemia which was identified. Lastly, the questionnaire used in this study was not designated as a lipid specialized survey tool, and several dyslipidemia related risk factors such as intake of fat, intake of sugar, or physical activity were not included.

\section{Conclusion}

Gender heterogeneity was detected in the prevalence, age related trends and risk factor patterns of dyslipidemia in middle aged rural Chinese. Gender-specific estimates should be provided in future lipid prevalence surveys. This heterogeneity should be taken into consideration in population-level blood lipid management projects. The effectiveness of population-level blood lipid management and CVD primary prevention programs in China is expected to be improved if gender heterogeneity is considered.

\section{Supplementary information}

Supplementary information accompanies this paper at https://doi.org/10. 1186/s12944-020-01313-8.

Additional file 1: Supplementary Table 1. Definitions and coding forms for potential risk factors investigated in the ESECC trial from rural Hua County, China, 2012-2016. Supplementary Table 2. Selected demographic and behavioral characteristics in individuals enrolled in and excluded from the current study from the ESECC trial. Supplementary
Table 3. Age and gender specific mean level ( $\mathrm{mg} / \mathrm{dL})$ and prevalence of dyslipidemia among 26,378 participants from rural Hua County, China, 2012-2016. Supplementary Table 4. Associated factors for high dyslipidemia identified in stratification of gender from 26,378 participants from rural Hua County, China, 2012-2016. Supplementary Figure 1. Flowchart of participant enrollment in this study. Supplementary Figure 2. The age and gender distribution of prevalence of high TG, TC and LDL-C among 26,378 individuals from rural Hua County, China, 2012 2016. Supplementary Figure 3. The prevalence of high TC, high TG, high LDL-C and low HDL-C in individuals 40-69 years in the 2013-2014 China Chronic Disease and Risk Factor Surveillance (CCDRFS), The China National Survey of Chronic Kidney Disease (CKD) and dyslipidemia investigation in Chongqing.

\section{Abbreviations}

BHA: Borderline high and above; CVD: Cardiovascular disease; HDL-C: Highdensity lipoprotein cholesterol; LDL-C: Low-density lipoprotein cholesterol; TC: Total cholesterol; TG: Triglycerides

\section{Acknowledgements}

Not applicable.

\section{Authors' contributions}

Study concept and design: Yang Ke, Yangfeng Wu and Zhonghu He; acquisition of data: Zhonghu He, Mengfei Liu, Fenglei Li, Chuanhai Guo, Zhen Liu, Yaqi Pan, Ying Liu, Fangfang Liu, Hong Cai; analysis and interpretation of data: Minmin Wang, Mengfei Liu, Zhonghu He and Yang Ke; drafting of the manuscript: Minmin Wang, Zhonghu He, Mengfei Liu, and Yang Ke; statistical analysis: Minmin Wang, Mengfei Liu and Zhonghu He; study supervision: Yang Ke and Zhonghu He. The author(s) read and approved the final manuscript.

\section{Funding}

This work was supported by the charity project of the national ministry of health [grant number 201202014], the natural science foundation of China [grant numbers 81773501, 30930102, 81473033], the national key R\&D program of China [grant number 2016YFC0901404], the Digestive Medical Coordinated Development Center of Beijing Hospitals Authority [grant number XXZ0204], the science foundation of Peking University Cancer Hospital [grant numbers 2017-4, 2017-26] and the open project funded by the Key Laboratory of Carcinogenesis and Translational Research, Ministry of Education/Beijing [grant number 2017-10].

Availability of data and materials

The datasets used and/or analysed during the current study are available from the corresponding author on reasonable request.

\section{Ethics approval and consent to participate}

This study was approved by the institutional review board of the Peking University School of Oncology, China (No. 2011101110). Informed consent was obtained from each participant.

Consent for publication

Not applicable.

\section{Competing interests}

The authors declare that they have no competing interests.

\section{Author details}

${ }^{1}$ Key Laboratory of Carcinogenesis and Translational Research (Ministry of Education/Beijing), Laboratory of Genetics, Peking University Cancer Hospital and Institute, Beijing, China. 'Hua County People's Hospital, Anyang, China. ${ }^{3}$ Peking University Clinical Research Institute, Beijing, China.

Received: 15 October 2019 Accepted: 4 June 2020

Published online: 12 June 2020

References

1. Shepherd J. Lipoprotein metabolism. An overview. Drugs. 1994;47(Suppl 2): $1-10$. 
2. Joint Committee for Developing Chinese guidelines on Prevention and Treatment of Dyslipidemia in Adults. Chinese guidelines on prevention and treatment of dyslipidemia in adults. Zhonghua Xin Xue Guan Bing Za Zhi. 2007:35(5):1-30

3. Zhu J. Guidelines for prevention and treatment of dyslipidemia in Chinese adults (revised 2016). Zhongguo Xun Huan Za Zhi. 2016:31(10):937-53.

4. Executive Summary of The Third Report of The National Cholesterol Education Program (NCEP). Expert panel on detection, evaluation, and treatment of high blood cholesterol in adults (Adult treatment panel III). JAMA. 2001:285(19):2486-97.

5. Nordestgaard BG. Triglyceride-rich lipoproteins and atherosclerotic cardiovascular disease: new insights from epidemiology, genetics, and biology. Circ Res. 2016;118(4):547-63.

6. The Emerging Risk Factors Collaboration, Di Angelantonio E, Sarwar N, Perry P, Kaptoge S, Ray KK, et al. Major lipids, apolipoproteins, and risk of vascular disease. JAMA. 2009;302(18):1993-2000.

7. Sun L, Clarke R, Bennett D, Guo Y, Walters RG, Hill M, et al. Causal associations of blood lipids with risk of ischemic stroke and intracerebral hemorrhage in Chinese adults. Nat Med. 2019;25(4):569-74.

8. Franklin BA, Durstine $\mathrm{J}$, Roberts CK, Barnard RJ. Impact of diet and exercise on lipid management in the modern era. Best Pract Res Clin Endocrinol Metab. 2014;28(3):405-21.

9. Zhang $M$, Deng $Q$, Wang L, Huang Z, Zhou M, Li Y, et al. Prevalence of dyslipidemia and achievement of low-density lipoprotein cholesterol targets in Chinese adults: a nationally representative survey of 163,641 adults. Int J Cardiol. 2018;260:196-203.

10. Pan L, Yang Z, Wu Y, Yin RX, Liao Y, Wang J, et al. The prevalence, awareness, treatment and control of dyslipidemia among adults in China. Atherosclerosis. 2016;248:2-9.

11. Qi L, Ding X, Tang W, Li Q, Mao D, Wang Y. Prevalence and risk factors associated with dyslipidemia in Chongqing, China. Int J Environ Res Public Health. 2015;12(10):13455-65.

12. Ni WQ, Liu XL, Zhuo ZP, Yuan XL, Song JP, Chi HS, et al. Serum lipids and associated factors of dyslipidemia in the adult population in Shenzhen. Lipids Health Dis. 2015;14:71.

13. Sun G-Z, Li Z, Guo L, Zhou Y, Yang H-M, Sun Y-X. High prevalence of dyslipidemia and associated risk factors among rural Chinese adults. Lipids Health Dis. 2014:13:189.

14. Li J-H, Wang L-M, Li Y-C, Bi Y-F, Jiang Y, Mi S-Q, et al. Epidemiologic characteristics of dyslipidemia in Chinese adults 2010. Zhonghua yu fang yi xue za zhi. 2012;46(5):414-8.

15. Cai L, Zhang L, Liu A, Li S, Wang P. Prevalence, awareness, treatment, and control of dyslipidemia among adults in Beijing, China. J Atheroscler Thromb. 2012;19(2):159-68.

16. Yang W, Xiao J, Yang Z, Ji L, Jia W, Weng J, et al. Serum lipids and lipoproteins in Chinese men and women. Circulation. 2012;125(18):2212-21.

17. Gao W, Wenhua Z, Kong L. Adult dyslipidemia health management service pilot project in China. Zhonghua Jian Kang Guan Li Za Zhi. 2018;12(4):2979.

18. Ying F, Tonghai $Y$, Wang $R$, Xie K. Analysis on the effect of health Management of Individuals with dyslipidemia in Luohu District, Shenzhen. Zhongguo Chu Ji Wei Sheng Bao Jian. 2016;30(2):46-7.

19. Zhipeng Z, Xie J, Xueli Y, Wenqing N, Hongshan C, Jinping S, Yang H, Xu J. Cost- effectiveness analysis of comprehensive community intervention and health management of patients with dyslipidemia in Shenzhen. Zhonghua Jian Kang Guan Li Za Zhi. 2018;12(4):313-8.

20. He Z, Liu Z, Liu M, Guo C, Xu R, Li F, et al. Efficacy of endoscopic screening for esophageal cancer in China (ESECC): design and preliminary results of a population-based randomised controlled trial. Gut. 2019;68(2):198-206.

21. Chen W-W, Gao R-L, Liu L-S, Zhu M-L, Wang W, Wang Y-J, et al. China cardiovascular diseases report 2015: a summary. J Geriatr Cardiol. 2017;14(1): $1-10$.

22. Weiwei C, Runlin G, Lisheng L, Manlu Z, Wen W, Yongjun W, et al. Outline of the report on cardiovascular diseases in China, 2014. Eur Heart J Suppl. 2016;18:F2-F11.

23. Boo S, Yoon YJ, Oh H. Evaluating the prevalence, awareness, and control of hypertension, diabetes, and dyslipidemia in Korea using the NHIS-NSC database: a cross-sectional analysis. Medicine (Baltimore). 2018;97(51): e13713
24. Park E, Kim J. Gender- and age-specific prevalence of metabolic syndrome among Korean adults: analysis of the fifth Korean National Health and nutrition examination survey. J Cardiovasc Nurs. 2015;30(3):256-66.

25. Marquezine GF, Oliveira CM, Pereira AC, Krieger JE, Mill JG. Metabolic syndrome determinants in an urban population from Brazil: social class and gender-specific interaction. Int J Cardiol. 2008;129(2):259-65.

26. Joshi SR, Anjana RM, Deepa M, Pradeepa R, Bhansali A, Dhandania VK, et al. Prevalence of dyslipidemia in urban and rural India: the ICMR-INDIAB study. PLoS One. 2014;9(5):e96808.

27. Lizcano F, Guzman G. Estrogen deficiency and the origin of obesity during menopause. Biomed Res Int. 2014:2014:757461.

28. Mendelsohn ME. Protective effects of estrogen on the cardiovascular system. Am J Cardiol. 2002;89(12A):12E-7E discussion 17E-18E.

29. Cignarella A, Kratz M, Bolego C. Emerging role of estrogen in the control of cardiometabolic disease. Trends Pharmacol Sci. 2010;31(4):183-9.

30. Jouyandeh Z, Nayebzadeh F, Qorbani M, Asadi M. Metabolic syndrome and menopause. J Diabet Metab Disord. 2013;12(1):1.

31. Song P-K, Li H, Man Q-Q, Jia S-S, Li L-X, Zhang J. Trends in determinants of hypercholesterolemia among Chinese adults between 2002 and 2012: results from theNational nutrition survey. Nutrients. 2017;9(3):279.

32. Ridker PM. LDL cholesterol: controversies and future therapeutic directions. Lancet. 2014:384(9943):607-17.

33. Nordestgaard BG, Varbo A. Triglycerides and cardiovascular disease. Lancet. 2014:384(9943):626-35.

34. Rader DJ, Hovingh GK. HDL and cardiovascular disease. Lancet. 2014; 384(9943):618-25.

35. Canner PL, Berge KG, Wenger NK, Stamler J, Friedman L, Prineas RJ, et al. Fifteen year mortality in coronary drug project patients: long-term benefit with niacin. J Am Coll Cardiol. 1986;8(6):1245-55.

36. Barter PJ, Caulfield M, Eriksson M, Grundy SM, Kastelein JJP, Komajda M, et al. Effects of Torcetrapib in patients at high risk for coronary events. N Engl J Med. 2007;357(21):2109-22.

37. Schwartz GG, Olsson AG, Abt M, Ballantyne CM, Barter PJ, Brumm J, et al. Effects of dalcetrapib in patients with a recent acute coronary syndrome. $\mathrm{N}$ Engl J Med. 2012;367(22):2089-99.

\section{Publisher's Note}

Springer Nature remains neutral with regard to jurisdictional claims in published maps and institutional affiliations.

Ready to submit your research? Choose BMC and benefit from:

- fast, convenient online submission

- thorough peer review by experienced researchers in your field

- rapid publication on acceptance

- support for research data, including large and complex data types

- gold Open Access which fosters wider collaboration and increased citations

- maximum visibility for your research: over $100 \mathrm{M}$ website views per year

At BMC, research is always in progress.

Learn more biomedcentral.com/submissions 